\title{
ATUAÇÃO DA PSICOLOGIA FRENTE À IDENTIDADE DE GÊNERO: UMA NOVA VISÃO
}

\section{Karla Luana Ávila de Borba ${ }^{1}$; Daiara Machado da Silva ${ }^{2}$; Ligia Zorzi Gomes ${ }^{3}$; Verônica Bidigaray Sanches ${ }^{4}$; Felix Miguel Nascimento Guazina ${ }^{5}$;}

\section{RESUMO}

A adolescência é uma fase de indagações e mudanças, onde surgem questões sobre autoconhecimento, sexualidade, autoaceitação e tantas outras. Este artigo trata-se de uma revisão de literatura, foi realizado por uma psicóloga residente em saúde mental, que atua em um Centro de Atenção Psicossocial (CAPS) Infantil, onde há o atendimento de um grande número de adolescentes. O estudo objetivou conhecer as produções teóricas atuais com enfoque na despatologização dentro do campo da saúde mental, buscando assim, uma melhora no acolhimento e no atendimento das pessoas trans. Concluiu-se que a psicologia tem um papel significativo como atuante e pioneira em agir na defesa e no esclarecimento das questões ligadas à temática trans.

Palavras-chave: Despatologização; Transexualidade; Transgênero.

Eixo Temático: Direitos, Políticas Públicas e Diversidade.

\section{INTRODUÇÃO}

Este artigo foi construído por uma psicóloga residente em saúde mental, durante o desenvolvimento de sua prática. De acordo com o MEC (2009), as residências multiprofissionais são uma modalidade de ensino de pós-graduação lato sensu, destinada aos profissionais da área da saúde, orientados pelos princípios e

\footnotetext{
${ }_{1}$ Psicóloga - Residente em Saúde Mental - UFN karla.avila@ufn.edu.br

2 Farmacêutica - Residente em Saúde Mental - UFN daiara.machado@ufn.edu.br

${ }^{3}$ Terapeuta Ocupacional - Residente em Saúde Mental - UFN ligia.zorzi@ufn.edu.br

${ }^{4}$ Assistente Social - Residente em Saúde Mental - UFN veronica.sanches@ufn.edu.br

${ }^{5}$ Coordenador - Coordenador da Residência Multiprofissional - UFN felix@ufn.edu.br
} 
diretrizes do Sistema Único de Saúde (SUS), a partir das necessidades e realidades locais e regionais.

A prática ocorreu em um Centro de Atenção Psicossocial (CAPS) Infantil, onde além de crianças há o atendimento de um grande número de adolescentes. Segundo o Ministério da Saúde (2011), o CAPS infantil é um componente da rede de atenção à saúde mental que oferece atendimento para crianças e adolescentes portadores de transtornos mentais severos e persistentes e,/ou, dependentes de álcool ou outras drogas.

Sabemos que a adolescência é uma fase de indagações e mudanças, onde surgem questões sobre autoconhecimento, sexualidade, autoaceitação e tantas outras. Junto com essas questões emergem dúvidas como: Quem sou eu no mundo? Como as pessoas me vêm? Qual papel desempenho frente à sociedade?

Ultimamente a mídia, as redes e os movimentos sociais, têm trazido à tona e ao conhecimento de um número maior de pessoas, questões até então pouco discutidas, que antigamente eram invisibilizadas, como a identidade de gênero, o papel de gênero e a transexualidade. É sobre esse universo que o presente trabalho irá discorrer, sobre a importância da despatologização no atendimento de adolescentes que se vêm imersos nessa nova configuração.

\section{METODOLOGIA}

O presente estudo se refere a uma revisão da literatura, que pretende contribuir para esclarecimentos na área de atuação da psicologia, diante das novas demandas encontradas dentro da temática da identidade de gênero e seus desdobramentos.

De acordo com Gil (2010) esse tipo de pesquisa é elaborada com base em material já publicado como livros, revistas, jornais, teses, dissertações e anais de eventos científicos, a partir de fontes impressas ou eletrônicas.

Objetivou-se conhecer as produções teóricas atuais com enfoque na despatologização dentro do campo da saúde mental, buscando assim, uma melhora no acolhimento e atendimento das pessoas trans. 
Este artigo foi realizado por uma aluna residente em saúde mental, do núcleo da psicologia. E a prática esteve vinculada á Universidade Franciscana (UFN) e foi vivenciada em um CAPS infantil no interior do Rio Grande do Sul.

\section{DISCUSSÃO}

Em um primeiro momento se faz necessário conhecer, mesmo que resumidamente, alguns pressupostos básicos, que servirão de alicerce para seguirmos no caminho da descoberta das singularidades que envolvem a pessoa trans.

Primeiramente devemos compreender que a sexualidade é uma construção biopsicossocial e histórica. Sua complexidade está ligada a uma gama de sentimentos, atração e comportamentos que nem sempre poderão ser alterados. (SILVA e MELLO, 2017).

A teoria de Picazio envolvendo os quatro pilares da sexualidade nos é apresentada por Silva e Melo (2017), sendo esses pilares divididos em: sexo biológico, papel sexual, orientação sexual e identidade sexual. O autor nos esclarece que o sexo biológico se refere a características anatômicas (genitais), ou seja, características genotípicas e fenotípicas do corpo humano. Já o papel sexual estaria ligado aos comportamentos que são considerados adequados ou não a cada gênero, levando em consideração o contexto sociocultural em que a pessoa está inserida.

Seguindo essa linha, a orientação sexual seria definida como a direção do objeto de desejo erótico, e pela atração afetiva/sexual por um indivíduo que represente um determinado gênero. Por fim o conceito de identidade sexual é definido pela subjetivação e pelo reconhecimento que a pessoa tem em relação a sua identidade de gênero. Podendo assim, se identificar com o gênero feminino, masculino, ou ainda, com a combinação entre os dois. É importante ressaltar que, essa identificação nem sempre estará de acordo com o sexo biológico. (PICAZIO, apud Silva e Melo, 2017). Esta desconformidade entre gênero e sexo biológico resulta no sujeito trans, que será nosso objeto de estudo.

Uma das principais propostas da residência multiprofissional e da atuação dentro de um CAPS infantil é a importância que se dá ao atendimento em equipe multiprofissional, neste caso a equipe que esteve presente durante essa experiência 
foi composta por psicólogos, terapeuta ocupacional, assistente social, farmacêuticos, psiquiatra, psicopedagogo, educadores físicos, fonoaudiólogo e técnico em enfermagem.

De acordo com Athayde (2011) a atuação de uma equipe multiprofissional capacitada é de grande importância para se alcançar uma avaliação adequada, já que falhas nesse processo podem causar sofrimento psíquico nos pacientes. Torna-se uma necessidade que toda a equipe tenha a expertise para trabalhar com as diversas demandas que são recebidas e as mais variadas faces da saúde mental.

Esse relato de experiência se refere ao atendimento de adolescentes que trazem para o processo terapêutico uma nova temática no campo de atuação, relacionada a questões de identidade de gênero, mais precisamente transgêneros e transexuais.

No que se refere ao cuidado dessas pessoas, os dados mostraram ser indispensável que os profissionais que se propõem a trabalhar com as pessoas transexuais estejam capacitados, a fim de não promoverem um maior desconforto, sentimentos de exclusão e discriminação por desconhecimento ou curiosidade, [..] (SAMPAIO e COELHO, 2011, p 4).

Ainda segundo Sampaio e Coelho (2011, p. 4) "[...] A transexualidade não elimina a subjetividade de cada um e não impede que cada sujeito viva e entenda a sua transexualidade através das suas experiências pessoais." Mostrando assim que o desconforto e sofrimento psicológico dessas pessoas não advém somente do desencontro entre sexo biológico e o psíquico mas também de problemas enfrentados como discriminação, pressões familiares e sociais.

Ao chegarem aos serviços de saúde, os usuários trans, de acordo com Arán e Murta (2009), se encontram na maioria das vezes em uma condição de vulnerabilidade social, física e psíquica, o que torna o serviço oferecido não apenas responsável pelo tratamento em si mas também pela construção de uma rede de inclusão social e reconhecimento para estas pessoas.

A forma como a compreensão da temática trans varia entre os profissionais da saúde pode estar ligada a vivências pessoais e/ou ao referencial teórico profissional, por exemplo: 
Para a medicina, o sexo biológico é a referência para a determinação da identidade sexual dos sujeitos. Qualquer desvio em relação a essa norma médica é compreendido como um transtorno, que pode ser tratado cirurgicamente adaptando o corpo ao que o sujeito entende ser. (SAMPAIO e COELHO, 2013, p. 1).

Segundo os autores acima, com uma visão mais ampliada sobre o tema, as ciências sociais trazem uma crítica a biomedicina, discutindo as questões de gênero a partir das relações com as normas e os valores socioculturais.

Para Bento e Pelúcio (2012), se calar e concordar que o gênero siga sendo diagnosticado, em vez de reconhecido e questionado, é o mesmo que contribuir para que essas pessoas sigam habitando as margens da sociedade.

A partir de estudos de Sousa et al. (2021) o Brasil é considerado o país com maior número de mortes de pessoas trans de acordo com o Observatório de pessoas Trans Assassinadas, acredita-se que isso ocorra devido ao preconceito, estigmas e falta de empatia que essas pessoas sofrem por parte da população. A ascensão de partidos políticos de direita no país nos últimos anos pode ter contribuído por dificultar ainda mais a liberdade de viver em segurança dessas pessoas.

No que se refere à atuação do psicólogo frente ao tema, observamos que "O olhar da Psicologia para a transexualidade procura afastar-se da herança médicopsiquiátrica tradicional que a considera um transtorno mental, uma disforia de gênero" (GASPODINNI e RICCI, 2013, p.1).

Seguindo o pensamento desses autores, dentro desse conceito o papel fundamental da psicologia seria a promoção e o respeito à diversidade e as manifestações subjetivas dos sujeitos, criando assim práticas despatologizantes e um olhar embasado sócio-historicamente.

De acordo com Cannone (2019), houve uma luta árdua para a despatologização das identidades transexuais e travestis, que tem contado com a colaboração de diversos setores, como categorias profissionais e movimentos sociais.

Através dos Conselhos Federal e Regional da classe, a psicologia vem desde 2011 se posicionando institucionalmente a favor da despatologização da identidade de gênero. O CRP de São Paulo, em maio de 2011, demostrou seu apoio à Campanha 
Internacional "Stop Trans Pathologization - 2012", através do Manifesto pela Despatologização das Identidades Trans.

Em 2013, o Conselho Federal de Psicologia elaborou a nota técnica sobre processo transexualizador e demais formas de assistência às pessoas trans, onde enfatiza a despatologização, a garantia do respeito e de acompanhamento de qualidade, afirmando que $\mathrm{o}$ atendimento deve atender a todas as demandas psicossociais do sujeito e não deve se restringir aos casos de mudanças corporais. (CFP, 2013).

No ano de 2016, o CRP do Rio Grande do Sul publicou a nota técnica onde esclareceu sua posição diante do papel da/do profissional de psicologia na promoção da despatologização e da não estigmatização das identidades de transexuais e travestis. "[...] por entender que é compromisso de nossa categoria refletir sobre a incidência de nossa prática na promoção da autonomia e no exercício da liberdade de todas as pessoas." (CRP-RS, 2016, p. 3).

Outro marco importante foi em 2018, através da conquista obtida com a Resolução no 01/2018 que estabelece normas de atuação para psicólogas/os em relação às pessoas trans. Onde há nove artigos que norteiam as práticas Psi para o caminho de luta contra a discriminação, o preconceito e a conivência com discursos e ações estigmatizantes. (CRP-RS, 2018).

Observamos até então o engajamento da psicologia dentro desses movimentos. Mas e as outras profissões que também atuam na saúde mental? Como elas têm acompanhado essa nova abordagem?

Os olhares de preconceito ainda existem e as falas desleixadas e equivocadas parecem longe de terminar. Não estamos aqui querendo insinuar que a psicologia escapa a esses erros e que isso seria apenas um problema a ser trabalhado em outros núcleos, porém acredita-se que há uma legislação que nos orienta de maneira bem mais específica, nos mostrando questões éticas e diretrizes a serem seguidas.

O Conselho Federal de Psicologia (CFP) foi uma das principais e mais rápidas instituições brasileiras a reagir ao debate sobre a despatologização e, em determinados momentos, até mesmo protagonizá-lo. Além de uma série de debates em âmbito estadual e federal, em 2013, produziu a Nota técnica sobre processo transexualizador e demais formas de 
assistência às pessoas trans que explicitamente afirma considerar que a "transexualidade e a travestilidade não constituem condição psicopatológica, ainda que não reproduzam a concepção normativa de que deve haver uma coerência entre sexo biológico/gênero/desejo sexual" (COACCI, 2020, p. 12).

Com o passar do tempo, felizmente, novas teorias foram discutidas, trazendo reconhecimento e legitimidade à identidade de gênero, a desvinculando da patologização e da obrigatoriedade de estar associada necessariamente a disforia corporal, ou a outros transtornos mentais.

\section{CONCLUSÃO}

Conclui-se que precisamos conhecer melhor a temática trans se quisermos desenvolver um trabalho relevante em saúde mental, pois essa é uma demanda em ascendência. Respeitar a identidade de gênero das pessoas em qualquer ocasião é o mínimo a se fazer.

Usar a terminologia correta das palavras, perguntar o nome social e o pronome que gostaria de ser chamado, são atitudes simples que podem amenizar possíveis constrangimentos, isso deveria ocorrer em todos os locais da rede por onde essas pessoas passam e são atendidas por diversos profissionais. Sabemos que muitas pessoas ainda tem dificuldade em se adequar essas questões e fazem polêmica e o uso de preconceito ou descaso.

Mesmo com a recente luta pela despatologização da questão trans, encabeçadas por movimentos políticos, ciências sociais e da saúde, podemos observar que profissionais de diversas áreas ainda não estão preparados para trabalhar com essa nova demanda, seja por questões teóricas ou pessoais.

É possível observar o papel significativo do psicólogo como atuante e responsável em agir na defesa e no esclarecimento das questões ligadas às pessoas trans, pois somos uma área pioneira a seguir esse caminho. A psicologia pode atuar desmistificando o tabu que envolve esse tema que já nasceu envolto em discriminação e preconceito, levantando reflexões e discussões sobre a importância da despatologização na vida dessas pessoas, construindo assim novas formas de 
produção de saúde e o desenvolvimento de politicas públicas mais assertivas para essa população.

\section{REFERÊNCIAS}

ARÁN, M.; MURTA, D; Do diagnóstico de transtorno de identidade de gênero às redescrições da experiência da transexualidade: uma reflexão sobre gênero, tecnologia e saúde. Physis Revista de Saúde Coletiva, Rio de Janeiro, v. 19 [ 1 ]: p.15-41, 2009.

ATHAYDE, A. V. L. Transexualismo masculino. Arq Bras Endocrinol Metab, São Paulo, v. 45, n. 4, p. 407-414, Aug. 2001.

BENTO, B; PELÚCIO, L. Despatologização do Gênero: Politização das Identidades Abjetas. Revista Estudos Feministas, Florianópolis, v. 20, n. 2, p. 569-581, maio/ago. 2012.

BRASIL. Ministério da Saúde. Secretaria de Atenção à Saúde. Portaria no 457, Aprova a Regulamentação do Processo Transexualizador no âmbito do Sistema Único de saúde - SUS, de 19 de agosto de 2008.

BRASIL, Portaria Interministerial mec/ms no 1.077, de 12 de novembro de 2009. Dispõe sobre a Residência Multiprofissional em Saúde e a Residência em Área Profissional da Saúde, e institui o Programa Nacional de Bolsas para Residências Multiprofissionais e em Área Profissional da Saúde e a Comissão Nacional de Residência Multiprofissional em Saúde. Diário Oficial da União; Poder Executivo, Brasília, DF, 13 nov. 2009.

BRASIL, Portaria no 3.088, de 23 de dezembro de 2011. Institui a Rede de Atenção Psicossocial para pessoas com sofrimento ou transtorno mental e com necessidades decorrentes do uso de crack, álcool e outras drogas, no âmbito do Sistema Único de Saúde (SUS). Diário Oficial da União, Brasília, DF, 23 dez. 2011. 
CANNONE, L. A. R. Historicizando a Transexualidade em Direção a uma Psicologia Comprometida. Psicologia: Ciência e Profissão. v. 39, p. 21-34, 2019.

COACCI, T. A queima dos laudos: controvérsias e reconfigurações dos saberes e direitos trans na ADI 4275. Rev. Direito Práx., Rio de Janeiro, v. 11, n. 02, p. 11881210, 2020.

COHEN, C. Bioética e sexualidade nas relações profissionais. São Paulo: Associação Paulista, 1999.

CONSELHO FEDERAL DE PSICOLOGIA. Resolução № 1, que estabelece normas de atuação para as psicólogas e os psicólogos em relação às pessoas transexuais e travestis, de 29 de Janeiro de 2018.

CONSELHO FEDERAL DE PSICOLOGIA. Nota técnica sobre processo transexualizador e demais formas de assistência às pessoas trans, de 04 de Outubro de 2013.

CONSELHO REGIONAL DE PSICOLOGIA/RS. Nota Técnica do CRPRS acerca da produção de documentos psicológicos em situações de alteração/adequação de nome no registro civil e de procedimentos de modificação corporal de pessoas transexuais e travestis. Porto Alegre, 16 de Setembro de 2016.

CONSELHO REGIONAL DE PSICOLOGIA/SP. Manifesto: Pela despatologização das identidades trans (travestis, transexuais e transgêneros). São Paulo, 2011.

GASPODINI, B.; RISSI, V. Processo transexualizador: apontamentos sobre o papel do(a) psicólogo(a). Conferencia: VII Mostra de Iniciação Científica e Extensão Comunitária e VI Mostra de Pesquisa de Pós Graduação da IMED. Passo Fundo, Rio Grande do Sul, Brasil.

GIL, A. C. Como elaborar projetos de pesquisa. 5. ed. São Paulo: Atlas, 2010. 
ORGANIZAÇÃO MUNDIAL DA SAÚDE. Classificação de Transtornos Mentais e de Comportamento da CID-10: Descrições Clínicas e Diretrizes Diagnósticas. Porto Alegre: Artmed,1993.

SAMPAIO, L.L.P.; COELHO, M.T.A.D. A transexualidade no cenário brasileiro atual: a despatologização e o direito à identidade de gênero In: Anais do III Seminário Internacional Enlaçando Sexualidades. Salvador: UNEB, 2013.

SAMPAIO, L.L.P.; COELHO, M.T.A.D. A transexualidade na atualidade: discurso científico, político e histórias de vida In: Anais do III Seminário Internacional Enlaçando Sexualidades. Salvador: UNEB, 2013.

SAMPAIO, L.L.P.; COELHO, M.T.A.D. Transexualidade: aspectos psicológicos e novas demandas ao setor saúde. Interface (Botucatu), v. 16, n. 42, p. 637-649, 2012.

SAMPAIO, L.L.P.; COELHO, M.T.A.D. Quando o estranhamento se traduz em preconceito: trajetórias de vida de pessoas transexuais. In: Minorias Sexuais: direitos e preconceitos. Brasília - DF: Consulex, p. 341-351, 2011.

SILVA, F. A.; MELLO I. S. P. B. Psicologia e a despatologização da transexualidade. Tempus, actos de saúde coletetiva, Brasília, v. 11(1), p. 81-95, mar, 2017.

SOUSA, C. H. B.; SOUSA, F.G.S.; FARIAS A. B.; VIANA, B. A. Transexualidade, preconceito e políticas públicas: formas de resistência e produção de saúde através da arte. Temática: Violência Contra as Mulheres e Desigualdade de Gênero e Raça. Periodicos Unicesumar, v. 23, n.1, 2021. 